Gut, 1987, 28, 849-854

\title{
Adaptation of hydrogen analysis to measure stomach to caecum transit time in the rat
}

\author{
NICOLA J BROWN, R D E RUMSEY, AND N W READ \\ From the Sub Department of Human Gastrointestinal Physiology and Nutrition, Department of Physiology, \\ The University, Sheffield
}

SUMMARY Excreted hydrogen analysis was used to measure stomach to caecum transit time of the head of a test meal in 120 rats fed by gavage. Results were compared with the distribution of a labelled test meal in the gastrointestinal tract of rats killed at different time intervals after gavage. Values for stomach to caecum transit were compatable with the distribution of labelled meals in $91 \%$ of animals, although in the remainder the hydrogen concentration had not risen even though food residues were in the caecum when the animals were killed. The technique gave reproducible results; the coefficients of variation for four studies carried out in each of six animals varied between 4 and $14 \%$. A meal consisting of homogenised baked beans had a significantly shorter stomach to caecum transit time $(88 \cdot 1 \pm 4.5 \mathrm{~min} ;$ mean $\pm S E ; n=21 ; p<0 \cdot 001)$ than an equivalent volume of Complan/lactulose $(180.9 \pm 8.7 \mathrm{~min} ; \mathrm{n}=13)$. This technique was used to investigate the effect of ileal infusion of a fat emulsion (20\% Intralipid) via a chronically implanted intestinal cannula on the stomach to caecum transit time of a bean meal, in a series of paired studies carried out in six rats. Stomach to caecum transit time was significantly delayed during ileal infusion of $20 \%$ Intralipid compared with the control infusion of an isotonic saline solution $(218.3 \pm 21 \mathrm{~min} v$ $106 \cdot 7 \pm 33$ min Intralipid $v$ saline; $\mathrm{n}=6 ; \mathrm{p}<0 \cdot 001)$.

The entry of unabsorbable carbohydrate into the colon leads to the rapid production of hydrogen gas by colonic bacteria. ${ }^{1-3}$ The gas diffuses rapidly through the body tissues and is excreted in the breath. Breath hydrogen analysis has been used in man to determine the time taken for the head of a test meal containing unabsorbable carbohydrate to reach the colon. ${ }^{2}$ The aim of this series of experiments was to adapt the technique for use in small mammals so that measurements of small bowel transit could be carried out in the same animals on several occasions and under experimental conditions that would be inappropriate for normal human subjects.

The reproducibility of repetitive measurements of stomach to caecum transit time has been assessed. Profiles of postprandial hydrogen excretion have

Address for correspondence: N J Brown, Sub Department of Human Gastrointestinal Physiology and Nutrition, Department of Physiology. The University, Western Bank, Sheffield S10 2TN.

Received for publication 7 November 1986. been compared with the distribution of a labelled meal in the gastrointestinal tract, determined by killing the animals at different times after gavage and estimating the distribution of radioactivity. ${ }^{4}$ Finally in order to show the utility of this technique, studies were carried out to investigate whether ileal infusion of Intralipid causes a delay in stomach to caecum transit in the rat, similar to the delay in mouth to caecum or duodenum to caecum transit observed in man. ${ }^{5}$

\section{Methods}

ANIMALS

Experiments were carried out on a total of 132 adult male albino rats, obtained from Sheffield Field Laboratories and weighing between 250 and $300 \mathrm{~g}$. They were allowed free access to food (Diet 86, Oxoid, London, UK) and water until 18 hours before the experiment. 
USE OF HYDROGEN ANALYSIS TO MEASURE STOMACH TO CAECUM TRANSIT TIME

Stomach to caecum transit time of the head of a test meal containing a source of unabsorbable carbohydrate was assessed by determining the rise in hydrogen in the rat's environment, that occurred when the carbohydrate reached the colon and was fermented by colonic bacteria. ${ }^{12}$

On the morning of the experiment, $5 \mathrm{ml}$ of a labelled test meal was given by gavage. Immediately after gavage, each rat was placed in an airtight desiccator (volume 10 litres). Air was infused into the top of the desiccator at a rate of $50 \mathrm{ml} / \mathrm{min}$ via a threeway tap system, and allowed to escape from the base of the desiccator via a flow meter. Soda-lime and silica-gel (BDH Chemicals Ltd, Poole, UK) were used to absorb water vapour and carbon dioxide respectively. The gas composition inside the desiccator was sampled every 10 minutes throughout the experiment and analysed for hydrogen concentration by means of a polarographic hydrogen monitor (GMI Medical Ltd, Renfrew, Scotland, UK) which had been calibrated with a standard gas mixture.

The hydrogen concentrations were plotted against time from gavage (Fig 1a). Stomach to caecum transit time of the head of the test meal was defined as the time from gavage to an increase in the hydrogen concentration in the rats enviroment of 2 parts per million (ppm) above basal values, sustained for at least three successive readings. In order to check the validity of the point of hydrogen rise, values were also plotted in the form of a cumulative sum chart (Fig 1b), which allows a more accurate determination of the stomach to caecum transit time. 'Cumulative sum' is an iterative technique which sums the progressive deviation of hydrogen concentration from a baseline value, in this case the stable hydrogen concentration before a rise is perceived, and thus emphasises the point at which the hydrogen concentration begins to increase consistently.

(a)
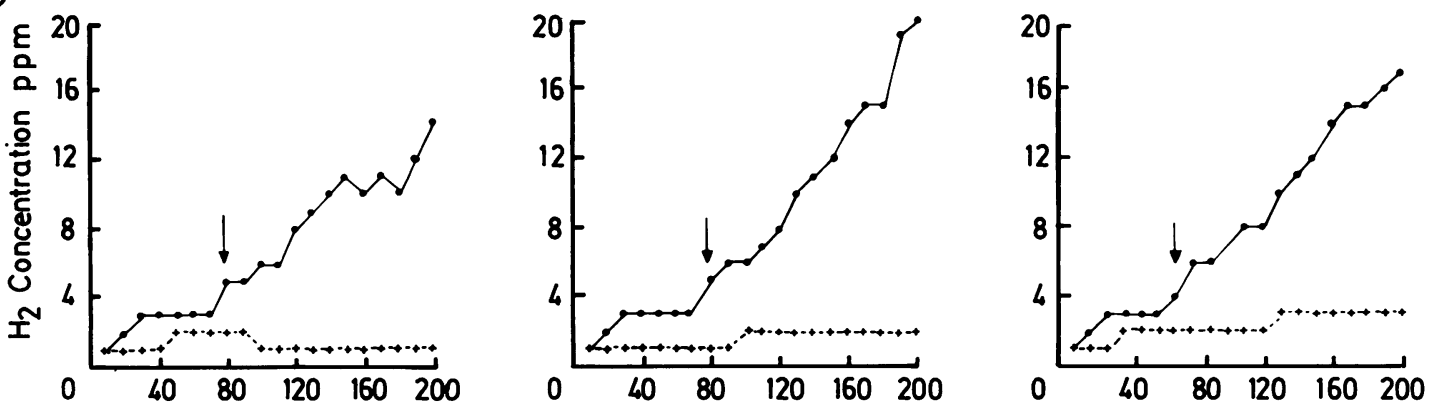

(b)
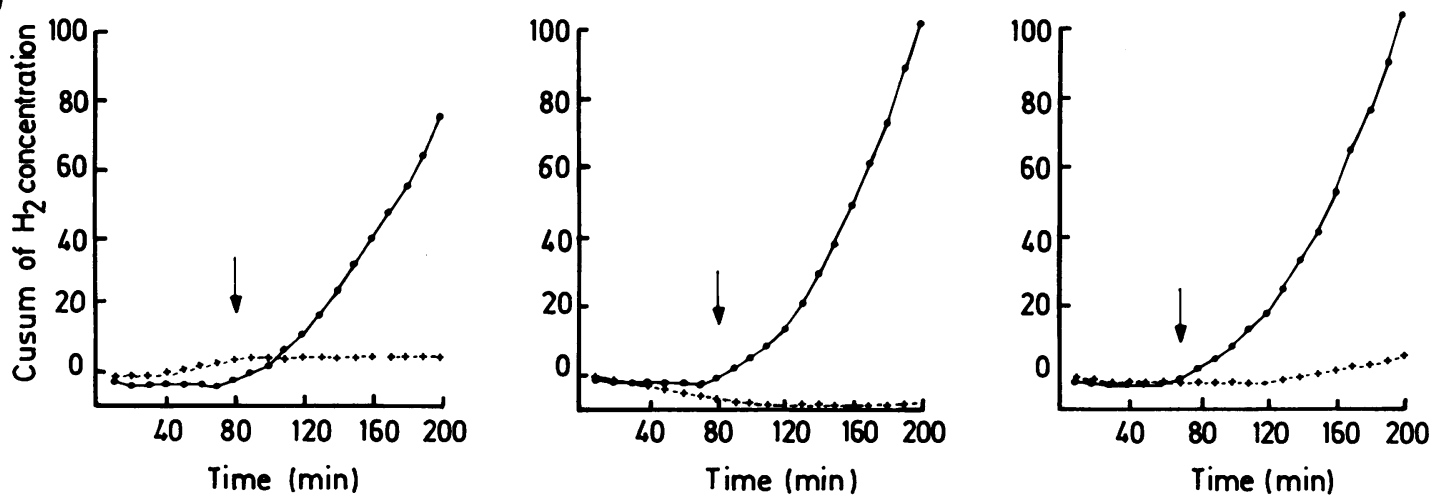

Fig. 1 Typical profiles of hydrogen concentration in the rats environment under fasting conditions $(-+-+-+-)$ and after ingestion of the baked bean meal (closed circles) in the same three animals. The time from gavaging the animal with a meal to the rise in hydrogen concentration is the stomach to caecum transit time of the head of the meal and is indicated by the arrows. The same data are represented as (a) a profile of the absolute hydrogen concentrations $(p p m)$ and $(b)$ the cumulative sum plot of the data, obtained every 10 minutes throughout the experiment. 
Measurements were also carried out in 24 fasted rats to determine the time taken for basal hydrogen concentrations to equilibrate in the rats enviroment.

COMPARISON OF HYDROGEN ANALYSIS WITH THE DISTRIBUTION OF THE MEAL

The profile of hydrogen concentration obtained from within the rats' environment was compared with the position of the head of the labelled test meal in a total of 120 rats (including the 24 rats used to obtain basal hydrogen values); equal numbers being killed at 50 , 100,200 , and 300 minutes after gavage. Two different labelled test meals $(5 \mathrm{ml})$ were administered to a total of 120 rats. Forty eight rats received homogenised baked 'Californian' white beans (washed to remove the tomato sauce, H J Heinz Co Ltd, Hayes, Middlesex, UK), labelled with $25 \mu \mathrm{Ci}{ }^{{ }^{4} \mathrm{~m}} \mathrm{Tc}$-tin colloid (0.93 mBq; Amersham International, Buckinghamshire, UK), which was added to $0.5 \mathrm{ml}$ of water used to homogenise the beans. The osmolality of the bean meal was $390 \mathrm{mOsmol} / \mathrm{kg}$, and $100 \mathrm{~g}$ of beans contained $0.1 \mathrm{~g}$ fat. A further 72 rats received a mixture of Complan and lactulose (15 g Complan: $50 \mathrm{ml}$ of $10 \%$ Duphalac [lactulose $33.5 \mathrm{~g}$, lactose $<3 \mathrm{~g}$, galactose $<5.5 \mathrm{~g}$ ] Duphar, Weesp, Holland), labelled with $0.1 \mathrm{~g}$ charcoal (Norit GSX, NoritClydesdale Co Ltd, Glasgow, Scotland, UK). Complan (Farley Health Products Ltd, Plymouth, Devon, UK) contains approximately $20 \%$ protein, $16 \%$ fat, and $55 \%$ carbohydrate. The osmolality of the Complan/lactulose meal was $800 \mathrm{mOsmol} / \mathrm{kg}$. Beans, Complan and lactulose all contain unabsorbable carbohydrate, the substrate from which colonic bacteria produce the hydrogen gas measured throughout the experiments. The amount of unabsorbable carbohydrate in Complan was unknown, so lactulose was added to the meal to ensure that there was sufficient unabsorbable carbohydrate to give a hydrogen rise.

After the animal was killed, the intestine was ligated at the lower oesophageal sphincter, the pylorus and the ileocaecal valve. The whole of the gastrointestinal tract from stomach to colon was removed carefully with the minimum handling to avoid stretching and movement of intestinal contents, and placed in a plastic trough. The unstretched length of intestine between the pylorus and the ileocaecal valve, and the distance from the head of the charcoal labelled meal to the pylorus were measured, and expressed as a percentage of the total length of the small intestine.

The distribution of the radiolabelled meal within the intestine was determined by pulling the trough under a crystal scintillation detector (Type DMI-2, Nuclear Enterprises Ltd, Edinburgh, Scotland, UK) at a constant rate of $10 \mathrm{~cm} / \mathrm{min}$. The scintillation detector was fitted with a slit-slaped collimator $(6 \mathrm{~mm}$ in diameter) and was connected to a counter ratemeter (Type MS310E, J \& P Engineering (Reading) Ltd, Reading, UK). The resulting radioactivity profile (Fig. 2) was displayed on a chart recorder, also driven at $10 \mathrm{~cm} / \mathrm{min}$.

\section{ASSESSMENT OF REPRODUCIBILITY}

Measurements of stomach to caecum transit time using environmental hydrogen analysis was assessed on four separate occasions in six animals. Rats were gavaged with a mixture of $5 \mathrm{ml}$ baked beans and $0.5 \mathrm{~g}$ lactulose $(520 \mathrm{mOsmol} / \mathrm{kg})$. Lactulose was added to increase the unabsorbable carbohydrate component of the meal. Studies were always carried out at the same time of the day and were separated by at least a week.

EFFECT OF ILEAL INFUSION OF INTRALIPID A plastic cannula (Silastic ID 0.02 in, OD $0 \cdot 037$ in, Dow Corning Corp, Medical Products, Midland, Michigan, USA), $25 \mathrm{~cm}$ in length, was implanted in the ileum of six animals under barbiturate anaesthesia (Sagatal $60 \mathrm{mg} / \mathrm{kg}$; May \& Baker Ltd, Dagenham, UK). The abdomen was opened through a midline incision and the cannula placed in the ileal lumen $20 \mathrm{~cm}$ proximal to the ileocaecal valve via a stab wound. The intestinal wound was closed by tying a purse string suture around the cannula. Enough
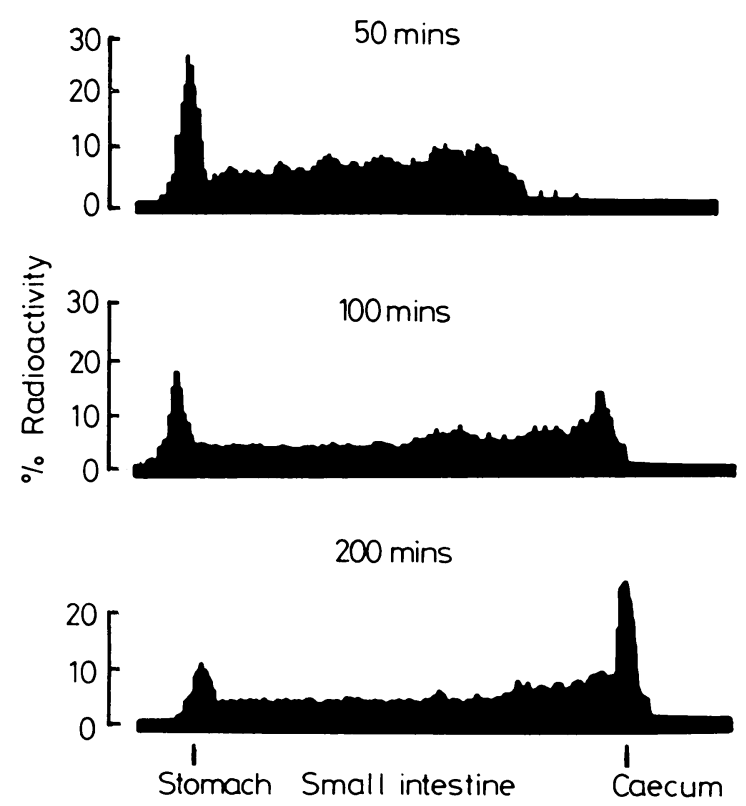

Fig. 2 A diagram to illustrate the typical distribution of a radiolabelled test meal in the gastrointestinal tract of rats killed at 50, 100, and 200 minutes after gavage. 
cannula was left free in the abdominal cavity to allow full mobility of the gastrointestinal tract. The cannula was tunnelled subcutaneously and exteriorised between the scapulae and the exposed end was covered with a blunt ended pin. Each rat was allowed a postoperative recovery period of one week before any experimental procedures were carried out.

Paired studies were carried out on each of six animals to determine the effect of ileal infusion of Intralipid (350 mOsmol/ $\mathrm{kg}$ ) on stomach to caecum transit time. After starvation for $18 \mathrm{~h}$, either $20 \%$ Intralipid (KabiVitrum Ltd, Uxbridge, UK) or $0.9 \%$ sodium chloride (Ivex Pharmaceuticals Ltd, Larne, $\mathrm{N}$ Ireland) were infused into the ileum at a rate of 0.3 $\mathrm{ml} / \mathrm{h}$. Twenty minutes after starting the infusion, the rats were gavaged with $5 \mathrm{ml}$ of the bean/lactulose meal and then placed in the desiccators. The infusion was continued for a further 165 minutes after gavage. The hydrogen concentration in the rats environment was monitored every 10 minutes throughout the experiment.

STATISTICAL ANALYSIS

The degree of statistical significance of the data was assessed using the Mann-Whitney $U$ test for nonparametric data and a one way analysis of variance test, where indicated.

\section{Results}

In fasted animals, the hydrogen concentrations took less than 20 minutes to equilibrate with the rats environment and then remained constant for the duration of the experiment (Fig. 1). The equilibration time was similar in the experiments where rats received a meal; the hydrogen concentration then remained constant, but started to increase 50 to 125 minutes after the bean test meal and 135 to 255 minutes after the Complan/lactulose test meal, continuing to rise for the remainder of the experiment (Fig. 1). The point at which the hydrogen concentration rose was the same irrespective of whether it was derived from the direct plots or the cumulative sum plots (Fig. 1).

\section{COMPARISON OF HYDROGEN ANALYSIS WITH} DISTRIBUTION OF THE TEST MEAL

The hydrogen analysis agreed with the distribution of the meal in 109 of $120(91 \%)$ rats. The meal had reached the caecum in 72 rats by the time they were killed. Sixty one of these animals showed a rise in hydrogen, and 11 showed no rise. Four showed a steady rise throughout the study. The meal had not reached the caecum by the time 48 of the animals were killed; none of these had shown a rise in hydrogen concentration.

\section{REPRODUCIBILITY OF THE HYDROGEN}

TECHNIQUE

Figure 3 shows four values for transit time of the head of bean/lactulose meal, determined on separate occasions over a period of a month for each of six animals. The data show little variation in values obtained within the same animal and from different animals. The coefficients of variation for the results from each individual rat were calculated using a one way ANOVA test. Values obtained were $13.9 \%$, $13 \cdot 3 \%, 11 \cdot 8 \%, 11 \cdot 2 \%, 8 \cdot 1 \%$, and $4 \cdot 4 \%$.

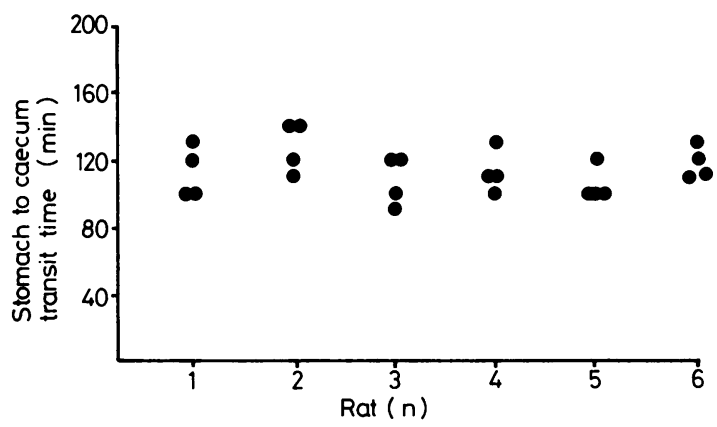

Fig. 3 Repeated stomach to caecum transit times of six rats gavaged with a test meal containing baked beans/lactulose.

EFFECT OF DIFFERENT MEALS

The transit time of the head of the Complan/lactulose meal $(180.9 \pm 8.7 \mathrm{~min} ; \mathrm{n}=13)$ was significantly longer than the transit time of the head of the bean meal (88.1 $\pm 4.5 \mathrm{~min} ; n=21 ; p<0.001)$. At 100 minutes after gavage the Complan/lactulose meal had reached a distance of $79 \cdot 2 \pm 3 \cdot 3 \%$ of the length of the small intestine and there was no rise in hydrogen, whereas the bean meal had moved all the way to the caecum in every rat and the hydrogen concentration had risen in each animal $(p<0 \cdot 001)$.

EFFECT OF ILEAL INFUSION OF INTRALIPID

Infusion of $20 \%$ Intralipid for 185 minutes significantly delayed the transit time of the head of a bean/lactulose meal when compared with a control infusion of isotonic saline $(218 \cdot 3 \pm 21 \mathrm{~min} v 106 \cdot 7 \pm 3 \cdot 3$ min; Intralipid $v$ saline; $\mathrm{p}<0 \cdot 001 ;$ Fig. 4).

\section{Discussion}

These experiments suggest that monitoring hydrogen concentrations in the environment is a useful means of measuring stomach to caecum transit in rats. The sensitivity of the hydrogen response to a meal appeared adequate; hydrogen concentrations in the environment of fasting rats stabilised rapidly and did not show a fluctuation in baseline. The times at which 


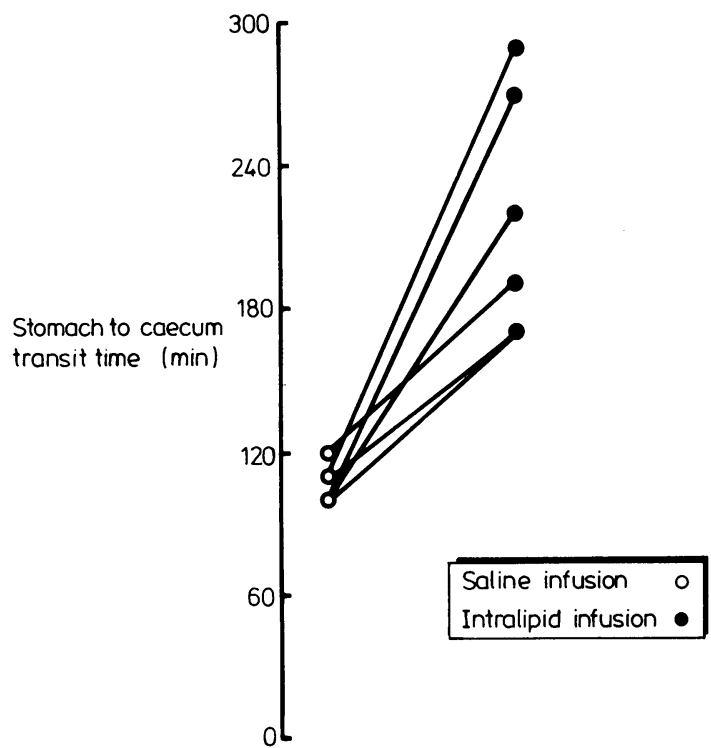

Fig. 4 The effect of ileal infusion of $20 \%$ Intralipid or isotonic saline on stomach to caecum transit time in six rats. The transit time of the head of the baked bean/lactulose meal was significantly delayed during ileal infusion of Intralipid, when compared with ileal infusion of saline (Mann-Whitney Utest, $p<0.001)$.

the hydrogen concentration rose after a meal were easily identified in all except the four animals in which the hydrogen concentration rose steadily throughout the experiment. As the meal had reached the colon in each of these animals by the time they were killed, it is possible that the transit of the head of the meal to the caecum was very rapid in these studies. The technique of gavaging was used to administer meals to the rats because we wanted to control the rate at which food entered the stomach. It is possible, however, that gavage may introduce a certain amount of stress when compared with normal eating patterns, and previous studies have shown that stress can influence gastric emptying ${ }^{7}$ and mouth to caecum transit time. ${ }^{8}$ If stress induced by gavage was an important influence on the data, we would have expected this to abate with the experience of the rat and vary on different occasions as the animal reacted to the procedure. In fact, animals adapted to gavage remarkably rapidly and did not struggle. Also the values obtained for stomach to caecum transit time showed a high degree of reproducibility both between rats and within the same rat.

The results of excreted hydrogen analysis corresponded with the distribution of the meal in $91 \%$ of animals, although in the remainder the meal was in the caecum while the hydrogen remained at basal values. In this small number of rats, it is possible that insufficient carbohydrate had entered the caecum to generate enough hydrogen to be detected in the rats environment. Studies in man have indicated that at least $0.5 \mathrm{~g}$ of unabsorbed carbohydrate is required to enter the caecum to generate a detectable rise in breath hydrogen. ${ }^{9}$

The hydrogen technique can be used repetitively on the same animal and measurements obtained under the same experimental conditions show good reproducibility. Using the technique in paired experiments carried out in the same animal on separate occasions, we showed that an infusion of $20 \%$ Intralipid into the ileum significantly delayed the stomach to caecum transit, compared with an infusion of isosmotic saline. These results are similar to those obtained in human subjects. ${ }^{5}$

The Complan/lactulose meal took more than twice as long as the bean meal to reach the caecum. This effect may be because of a delay in gastric emptying caused by the greater osmolality of the Complan/ lactulose meal..$^{10}$ Experiments in man, however, have shown that there is no relationship between the time for gastric emptying and mouth to caecum transit of the head of a meal. ${ }^{11}$ Moreover, recent studies have shown that increasing the osmolality of gastric solutions in rats from $300 \mathrm{mOsm} / \mathrm{kg}$ to $900 \mathrm{mOsm} / \mathrm{kg}$ did not influence gastric emptying rates. ${ }^{12}$ An alternative and more likely explanation is that the greater lipid content of the Complan/lactulose meal slowed mouth to caecum transit by interacting with ileal receptors. ${ }^{13}$

In conclusion the hydrogen technique is a convenient, useful and accurate method for measuring stomach to caecum transit time in rats. The equipment can be adapted so that measurements can be carried out on a number of animals simultaneously. ${ }^{14}$ An index of small bowel transit unaffected by the possible influences of gastric emptying, may also be obtained by infusing solutions containing unabsorbable carbohydrate directly into the duodenum via a chronically implanted cannula.

The technique could be applied to the study of many of the factors that influence small bowel motility and transit. In particular, it could be used to investigate the long term effects of drugs or alterations in diet, to study animals which have undergone procedures such as nerve section, intestinal resection, construction of chronic isolated intestinal loops, and implantation of serosal electrodes or intracerebroventricular cannulae, where death after each experiment is expensive in terms of time and materials.

The study was supported by a grant (no. 34137) from the Medical Research Council (UK). 


\section{References}

1 Bond JH, Levitt MD. Investigation of small bowel transit time in man utilising pulmonary hydrogen $\left(\mathrm{H}_{2}\right)$ measurements. J Lab Clin Med 1974; 85: 546-55.

2 Read NW, Miles CA, Fisher D, et al. Transit of a meal through the stomach, small intestine and colon in normal subjects and its role in the pathogenesis of diarrhoea. Gastroenterology 1980; 79: 1276-82.

3 Read NW, Al Janabi MN, Bates TE, Barber DC. Effect of gastrointestinal intubation on the passage of a solid meal through the stomach and small intestine in humans. Gastroenterology 1983; 84: 1568-72.

4 Derblom $H$, Johansson $H$, Nylander G. A simple method of recording quantitatively certain gastrointestinal motility functions in the rat. Acta Chir Scand 1966; 132: 154-65.

5 Read NW, McFarlane A, Kinsman RI, et al. The effect of infusion of nutrient solutions into the ileum on gastrointestinal transit and plasma levels of neurotensin and enteroglucagon. Gastroenterology 1984; 86: 274-80.

6 Woodward RH, Goldsmith PL. Cumulative sum techniques. Monograph 3. Mathematical and statistical techniques for industry. ICI. Edinburgh: Oliver and Boyd Ltd, 1964.

7 Spanghellini V, Malagelada JR, Zinsmeister AR, Go VLG, Koa PC. Stress induced gastroduodenal motor disturbances in humans: possible humoral mechanisms.
Gastroenterology 1983; 85: 83-91.

8 Cann PA. Read NW, Cammack J, et al. Psychological stress and the passage of a standard meal through the stomach and small intestine in man. Gut 1983; 24: 236-40.

9 Read NW, Al-Janabi MN, Bates TE, et al. Interpretation of the breath hydrogen profile obtained after ingesting a solid meal containing unabsorbable carbohydrate. Gut 1985; 26: 834-42.

10 Hunt JN. Some properties of an alimentary osmoreceptor mechanism. J Physiol 1956; 132: 267-88.

11 Read NW, Cammack J, Edwards C, Holgate AM, Cann $\mathrm{PA}$, Brown C. Is the transit of a meal through the small intestine related to the rate at which it leaves the stomach? Gut 1982; 23: 824-8.

12 Mogard MH, Nylander G, Flaten G, Hassen LE. Gastric emptying and intestinal transit of hyperosmolar solutions in relation to indomethacin and certain gut polypeptides in the rat. Scand J Gastroenterol 1986; 21: 348-52.

13 Jian R, Pecking A, Najean Y, Bernier JJ. Étude de la progression d'un repas dans l'intestin grele de l'homme par un methode scintigraphique. Gastroenterol Clin Biol 1979; 3: 755-62.

14 Brown NJ. An animal model for investigating the effect of infused nutrients into the ileum, on stomach to caecum transit time (SCTT) using the rat. [Abstract]. J Physiol 1986; 378: 14P. 